\title{
Review Paper: The Role of Health Centers Services for Response to COVID-19 in Iran
}

\author{
Hesam Seyedin' $^{1}$ (D), Fazeleh Sadat Sakhaei ${ }^{2}$ (D, Mohsen Dowlati ${ }^{\text {* }}$ (D) \\ 1. Department of Health in Disasters and Emergencies, School of Health Management and Information Sciences, Iran University of Medical Sciences, \\ Tehran, Iran. \\ 2. Department of Pediatrics \& Mental Health Nursing, School of Nursing and Midwifery, Iran University of Medical Sciences, Tehran, Iran.
}

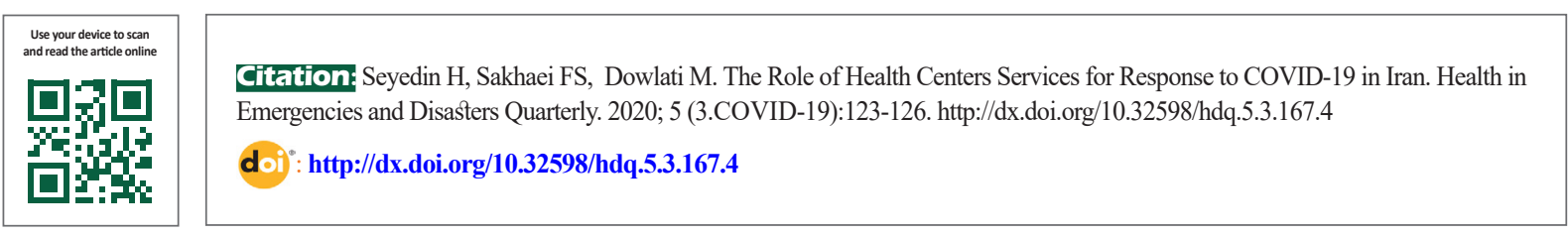

(c) (1) (5)

Article info:

Received: 05 Mar 2020

Accepted: 12 Mar 2020

Available Online: 01 Apr 2020

\section{Keywords:}

Health, COVID-19, Health

Centers, Pandemic

\begin{abstract}
Coronavirus disease 2019 (COVID-19) is a respiratory tract infection caused by a newly emergent coronavirus. Iran is one of the countries affected by the disease. Health center services have a critical role in response to the COVID-19 outbreak. This study with the aim of providing the functions and services of primary health care was performed by a health center in Iran during the COVID-19 outbreak. Based on the results, of the functions and services of the primary health care included purposive inter-organizational interaction and cooperation, risk analysis, planning, education and consultation, exercise, risk communication, environmental health, occupational health, and development of health infrastructures. Iran established and developed specific approaches for case identification, screening, and resource allocation to protect public health by primary health care services. Health center services are effective for a proper response to COVID-19 and a reduction in mortality by screening, rapid identification, and public education.
\end{abstract}

\section{Introduction}

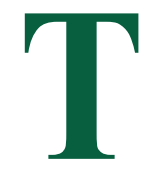

he coronavirus disease 2019 (COVID-19) is a highly transmittable and pathogenic viral infection caused by the severe acute respiratory syndrome coronavirus 2 (SARSCoV-2), which emerged in Wuhan, Hubei Province, China, and spread all over the world [1]. The World Health Organization (WHO) on May 7, 2020, confirmed 3.76 Million cases and 264000 deaths globally [2]. Iran is also one of the countries affected by the disease. As of May 7, 2020, until at the time of writing this paper, more than 102,000 cases of COVID-19 and 6418 deaths had been reported. COVID-19 seems to have different epidemiological characteristics of severe acute respiratory syndrome coronavirus (SARS-CoV) [3, 4]. The COVID-19 pandemic has caused serious threats to people's physical health and a wide variety of psychological problems, such as panic disorder, anxiety, and depression [5].

The health centers services are delivered by health professionals, doctors, and nurses working in general practices in urban, regional, rural, and remote locations across Iran. In the national response to the COVID-19 approach, it is recog-

\footnotetext{
* Corresponding Author:

Mohsen Dowlati, PhD.

Address: Department of Health in Disasters and Emergencies, School of Health Management and Information Sciences, Iran University of Medical

Sciences, Tehran, Iran.

E-mail: mohsendowlati.69@gmail.com
} 
nized that most vulnerable people and suspected COVID-19 cases receive their medical care and advice from primary care provided by the health centers. The health system of Iran has moved quickly in response to the threat of COVID-19.

Following the official start of counter operations to COVID-19, non-essential services were canceled, protective actions were considered for the high risk of the infection, and a strict social distancing was imposed along with quarantining of people with confirmed COVID-19 infection or those suspected. The four key objectives of the Primary Health Care Targeted Action Plan are as follows: protecting vulnerable people from the effects of COVID-19, preserving the functional capacity of the healthcare system, facilitating the most effective management of people with symptoms, and managing and maintaining the stocks of Personal Protective Equipment (PPE) [6]. This study was done to assess the functions and services of the primary health care provided by the health centers in Iran during the COVID-19 outbreak.

Purposive inter-organizational interaction and cooperation

At the time of the outbreak, different organizations with specified responsibilities should manage disasters. Successful management of the disasters requires cooperation among the responsible organizations to decrease the resulted casualties arisen by disasters. Inter-organizational interaction is considered as one of the frequent challenges, especially in the emergency conditions in response to disasters [7]. The organizations in charge should cooperate with each other as well as with the use of the other institution's potentialities in addition to fulfilling their own responsibilities, avoiding useless attempts, and interfering in non-related affairs, which are essential for the congruence and training before any disaster [8]. Cooperation between health centers and other sectors of the health system, especially hospitals, can result in better COVID-19 patient management.

\section{Risk analysis}

The characteristics and the extent of the risk can be determined by the risk-analysis procedure [9]. The risk analysis is performed based on the analysis of the potential risks as well as the evaluation of current harmful situations, which put people, their possessions, and their life at risk intensely [10]. The procedure of risk analysis is accomplished based on reviewing the technical aspects of risk, such as the place, intensity, quantity, and the probability of occurrence, as well as the analysis of physical, social, economic, and environmental aspects and the way to react against the hazard [11]. By performing risk assessment, the potential of the centers was identified to intervene in the epidemic conditions. Also, the vulnerability of the covered regions to the epidemic was examined for planning and necessary actions.

\section{Planning}

In order to counteract with disasters, such as the COVID-19 outbreak, a health center should have a plan for managing the hazards acknowledged by analyzing hazards and vulnerabilities, which should be based on primary health care facilities indices [12]. During an outbreak, health centers and hospitals face numbers of suspected and confirmed COVID-19 cases. Since primary health care facilities and hospitals are considered by their emergency services and round-the-clock activities, as vital centers for diagnosis, therapeutic approaches, and the proceedings by the therapeutic personnel, their preparedness to deal with the disasters and having a plan are definitely imperative [13]. The main aim of the preparedness plan is the reduction in the number of deaths, an increase in the number of people recovered, and the initial screening before hospital referral.

\section{Education and consultants}

Training and teaching the families appropriately for promoting the preparedness to respond to disasters can promote people's knowledge [14]. One of the main factors in the transmission and spreads of infection is the lack of knowledge about the disease. The teachings should be according to the issues, such as precaution measures, hand washing, self-care at home, and social distancing.

The establishment of call centers reduced unnecessary visits to hospitals through providing consultation and guidance to patients who might be at the risk of hospital-acquired infection, also known as a nosocomial infection. This consultation can also be provided through a telephone answering system. Public education includes providing basic health measures and providing guidelines on handwashing, disinfection of the surfaces, food hygiene, and also mental health support by experienced consultants.

\section{Exercise}

Simulation exercises are effective to develop, assess, and test the functional capabilities of emergency systems, procedures, and mechanisms to respond to disasters and emergencies [15]. The exercises are the activities designed for developing, improving, and approving the organizational qualifications and abilities, which are designed to accomplish one or several functions for the response to a disaster. These exercises are performed to empower the staff in the organizations and the general public to be prepared during disasters, improve the organization's capabilities to provide 
an effective response for real emergency conditions and recognize weak points and deficiencies of the sources, facilities, equipment, procedures, and the necessary actions for eliminating the existing challenges.

Health centers should consistently train activities, such as emergency operation plans, incident command systems, early warning systems, emergency evacuation, surge capacity, mass casualty incident triage, and care and therapeutic procedures.

\section{Risk communication}

During an outbreak, informing people and preventing them from spreading the rumors are of great importance. Risk communication is the effective and accurate exchange of information about health risks and hazards often during an outbreak that advances risk awareness and understanding and promotes health-protective behaviors among individuals, communities, and institutions [16]. Risk communication helps the decision-makers and beneficiaries to make conscious decisions, which results in effective management. During an outbreak, people look for news and information and are worried about their families. In addition to the classic media, the fast expansion of internet-based media, including social networks has accelerated communications, and people follow up the news mostly by social networks.

Appropriate use of media or broadcasting authentic news, and giving accurate practical recommendations to people play a significant role in reducing human, financial, and social loss due to disasters [17]. However, inauthentic information as well as improper use of media cause the propagation of rumors and contradictions in the information, resulting in increased anxiety [18]. Some of managers and executives consider the media as impediments for continuing services provided to people ignoring the significance of their informing-based vocation, whereas some others give them false information precipitously without considering its different consequences and authenticity, leading to the spreading of rumors, magnification of the incident, and some malicious persons' abuse of the situation, and anxiety and apprehension. On the other side, each organization should give information as much as its activities and duties are concerned.

\section{Environmental health}

Human coronaviruses can remain on surfaces for up to 9 days [19]. SARS-CoV-2 can remain up to $72 \mathrm{~h}$ in experimental conditions [20]. Therefore, environmental health measures are very necessary during the COVID-19 outbreak. Monitoring and inspection of different places should be performed by environmental health experts continuously.
These places include stores, bakeries, restaurants, gas stations, prisons, barracks, swimming pools, slaughterhouses, bus and train stations, offices, banks, hospitals, and places with the possibility of gatherings.

\section{Occupational health}

Following staff attendance in the workplace, the standard precaution of infection control should be applied. These measures include using PPE, hand hygiene, disinfection of the surfaces, such as tables, and maintaining the necessary distance with colleagues and clients.

\section{Development of health infrastructures}

After the disease outbreak, the health system infrastructures, including primary health services, healthcare systems, diagnostic laboratories, and organizations in charge of the drug, food, and drinking water supply should be developed. Also, for organizing the shortage of health staff, volunteers from other canters should be employed after training.

\section{Conclusion}

Iran established and developed specific approaches for case identification, screening, and resource allocation to protect public health by health center services. The effects of the disease can be diminished by raising people's awareness and health knowledge through education and consultation. Also, hospital workload and unnecessary hospital visits can be reduced by screening in health centers. Considering these findings, it can be concluded that primary health care services might are effective for the proper response to COVID-19 and a reduction in mortality by screening, rapid identification, and public education.

\section{Ethical Considerations}

\section{Compliance with ethical guidelines}

This is a review article and there were no ethical considerations to be considered in this research.

\section{Funding}

This research did not receive any grant from funding agencies in the public, commercial, or non-profit sectors.

\section{Authors' contributions}

All authors contributed in preparing this article. 


\section{Conflict of interest}

The authors declared no conflict of interests.

\section{Acknowledgments}

The authors would like to thank the School of Health Management and Information Sciences of Iran University of Medical Sciences.

\section{References}

[1] Shereen MA, Khan S, Kazmi A, Bashir N, Siddique R. COVID-19 infection: Origin, transmission, and characteristics of human coronaviruses. Journal of Advanced Research. 2020; 24:91-8. [DOI:10.1016/j.jare.2020.03.005] [PMID] [PMCID]

[2] Digital Assets. In: Coppola DP, editor. Introduction to International Disaster Management (Third Edition). Boston: Butterworth-Heinemann; 2015. p. xxi. https://www.elsevier.com/ books/introduction-to-international-disaster-management/coppola/978-0-12-801477-6

[3] Chan JF-W, Yuan S, Kok K-H, To KK-W, Chu H, Yang J, et al. A familial cluster of pneumonia associated with the 2019 novel coronavirus indicating person-to-person transmission: A study of a family cluster. 2020; 395 (10223):514-23. [DOI:10.1016/S01406736 (20)30154-9]

[4] Heymann DL, Shindo NJTL. COVID-19: What is next for public health? 2020; 395(10224):542-5. [DOI:10.1016/S0140$6736(20) 30374-3]$

[5] Qiu J, Shen B, Zhao M, Wang Z, Xie B, Xu YJGp. A nationwide survey of psychological distress among Chinese people in the COVID-19 epidemic: implications and policy recommendations. 2020; 33(2):e100213. [DOI:10.1136/ gpsych-2020-100213] [PMID] [PMCID]

[6] Kidd M. Australia's primary care COVID-19 response. Australian Journal of General Practice. 2020; 1-2. [DOI:10.31128/AJGP-COVID-02]

[7] Khorram-Manesh A, Lupesco O, Fried T, Arnim G, Kaptan K Djalali AR, et al. Education in disaster management: What do we offer and what do we need? Proposing a new global program. Disaster Medicine and Public Health Preparedness. 2016; 10(6):854-73. [DOI:10.1017/dmp.2016.88] [PMID]

[8] Rabiee A, Ardalan A, Poorhoseini SJHRJ. Assessment of coordination among lead agencies of natural disasters management in Iran. Hakim Health Systems Research Journal. 2013; 16(2):107-17. https://www.magiran.com/paper/1171688?lang=en

[9] Girgin S, Necci A, Krausmann E. Dealing with cascading multihazard risks in national risk assessment: The case of Natech accidents. International Journal of Disaster Risk Reduction. 2019; 35:101072. [DOI:10.1016/j.ijdrr.2019.101072.]

[10] Jaiswal R, Donahue J, Reilly MJ. Chapter 28 - Disaster Risk Management. In: Ciottone GR, editor. Ciottone's Disaster Medicine (Second Edition). Philadelphia: Elsevier; 2016. p. 167-77. [DOI:10.1016/B978-0-323-28665-7.00028-5] [PMCID]
[11] Jonidi Jafari A, Baba M, Dowlati M. Disaster Risk Assessment in Health Centers of Iran University of Medical Sciences in Functional, Non Structural \& Structural Components in 2015--2016. Iran Occupational Health Journal. 2018; 15(1):76-85. https:// www.researchgate.net/publication/326839556_Disaster_risk_ assessment_in_health_centers_of_Iran_University_of_Medical_Sciences_in_functional_non_structural_structural_components_during_2015-2016

[12] El Sayed M, Chami AF, Hitti E. Developing a hospital disaster preparedness plan for mass casualty incidents: Lessons learned from the downtown Beirut bombing. Disaster Medicine and Public Health Preparedness. 2018; 12(3):379-85. [DOI:10.1017/ dmp.2017.83] [PMID]

[13] Zhong S, Clark M, Hou XY, Zang YL, Fitzgerald GJEMJ. Development of hospital disaster resilience: Conceptual framework and potential measurement. Emergency Medicine Journal: EMJ. 2014; 31(11):930-8. [DOI:10.1136/emermed-2012-202282] [PMID]

[14] Torani S, Majd PM, Maroufi SS, Dowlati M, Sheikhi RA. The importance of education on disasters and emergencies: A review article.Journal of Education and Health Promotion. 2019; 8:85, [DOI:10.4103/jehp.jehp_262_18] [PMID] [PMCID]

[15] WHO. Strengthening health security by implementing the International Health Regulations (2005): Simulation exercise manual. Geneva: World Health Organization; 2017. https://www. who.int/ihr/publications/WHO-WHE-CPI-2017.10/en/

[16] DiClemente RJ, Jackson JM. Risk communication. In: Quah SR, editor. International Encyclopedia of Public Health ( $2^{\text {nd }}$ edition). Oxford: Academic Press; 2017. p. 378-82. [DOI:10.1016/B978-012-803678-5.00389-1]

[17] Radović V, Curčić L. The opportunities of crises and emergency risk communication in activities of serbian public health workforce in emergencies. Iranian Journal of Public Health. 2012; 41(10):15-23.

[18] Qiu W, Chu C, Hou X, Rutherford S, Zhu B, Tong Z, et al. A Comparison of China's Risk Communication in Response to SARS and H7N9 Using Principles Drawn From International Practice. Disaster Medicine and Public Health Preparedness. 2018; 12(5):587-98. [DOI:10.1017/dmp.2017.114] [PMID]

[19] Kampf G, Todt D, Pfaender S, Steinmann E. Persistence of coronaviruses on inanimate surfaces and its inactivation with biocidal agents. Journal of Hospital Infection. 2020; 104(3):246-51. [DOI:10.1016/j.jhin.2020.01.022] [PMID] [PMCID]

[20] van Doremalen N, Bushmaker T, Morris DH, Holbrook MG, Gamble A, Williamson BN, et al. Aerosol and surface stability of SARS-CoV-2 as compared with SARS-CoV-1. New England Journal of Medicine. 2020; 382:1564-7. [DOI $: 10.1101 / 2020.03 .09 .20033217]$ 